costs and treatment effects observed within the trial period and do not require extrapolation of effects beyond the trial period. However, modelling indicated that these longer term benefits are likely to double the mean difference in event-free time. Our results suggest that intensive management of patients with type 2 diabetes is a feasible and economically supportable option.

We thank the patients and staff at the study centres for their cooperation and Andrew Briggs, Philip Bassett, Valeria Frighi, and Ziyah Mehta for their contributions.

Contributors: AG helped plan and design the health economics study, supervised and participated in the analysis, coordinated the writing of the paper, and is the guarantor. MR compiled, maintained, and analysed the economic data and participated in interpreting the results and writing the paper. $\mathrm{AMcG}$ helped plan and design the health economics study and participated in supervising analysis, interpreting results, and writing the paper. PF helped plan and design the health economics study and participated in supervision and interpretation of results and revising the paper. RS developed the simulation model and participated in interpreting the results and writing the paper. CG was responsible for maintenance of the database, prepared trial data for analysis, discussed statistical aspects of the analysis, and participated in revising the paper. IS participated in data preparation, interpretation, and revision of the paper. AA helped to develop the simulation model and participated in interpreting the results and revising the paper. $\mathrm{RH}$ was a principal clinical investigator in the UK prospective diabetes study and participated in data preparation, analysis, and interpretation and revising the paper. RT was a principal clinical investigator in the clinical study, helped plan and design the study, and participated in interpreting the results and initial drafting of the paper. He died in August 1999.

Funding: Glaxo Wellcome, SmithKline Beecham, Pfizer, Zeneca, Pharmacia Upjohn, Novo Nordisk, Bayer, Roche, and UK Department of Health. RS is supported by a Wellcome Trust fellowship (grant No 054470/Z/98/Z/DG/NOS/FH). The main study was supported by grants from the UK Medical Research Council, British Diabetic Association, UK Department of Health, US National Eye Institute and National Institute of Diabetes, Digestive and Kidney Disease in the National Institutes of Health, British Heart Foundation, Novo Nordisk, Bayer, Bristol-Myers Squibb, Hoechst, Lilly, Lipha and Farmitalia Carlo Erba.

Competing interests: $\mathrm{RH}$ has received research for members of staff and fees for consulting and speaking, CC has received support for the cost of attending conferences, and AA has received fees for consulting from many of the companies who supported the study. AG has received support for attending conferences from Lipha.

1 The Diabetes Control and Complications Trial Research Group (DCCT). Lifetime benefits and costs of intensive therapy as practiced in the diabetes control and complications trial. JAMA 1996;276:1409-15.

2 Buxton M, Sculpher M, Ferguson B, Humphreys JE, Altman JF, Spiegelhalter DJ, et al. Screening for treatable diabetic retinopathy: a comparison of different methods. Diabetic Med 1991;8:371-7.

3 Sculpher M, Buxton M, Ferguson B, Spiegelhalter D, Kirby A. Screening for diabetic retinopathy: a relative cost-effectiveness analysis of alternative modalities and strategies. Health Economics 1992;1:39-52.

4 Eastman RC, Javitt JC, Herman WH, Dasbach EJ, Zbrozek AS, Dong F, et al. Model of complications of NIDDM. 1. Model of construction and assumptions. Diabetes Care 1997;20:725-34

5 Eastman RC, Javitt JC, Herman WH, Dasbach EJ, Copley MC, Maier W, et al. Model of complications of NIDDM. 2. Analysis of the health benefits and cost-effectiveness of treating NIDDM with the goal of normoglycemia. Diabetes Care 1997;20:735-44.

6 UK Prospective Diabetes Study Group. Intensive blood-glucose control with sulphonylureas or insulin compared with conventional treatment and risk of complications in patients with type 2 diabetes (UKPDS 33). Lancet 1998:352:837-53.

7 Netten A, Dennett J. Unit costs of community care. Canterbury: Personal Social Services Research Unit, University of Kent, 1998.

8 Treasury. Appraisal and evaluation in central government. London, Stationery Office, 1997

9 Willan AR, O'Brien BJ. Confidence intervals for cost-effectiveness ratios: an application of Fieller's theorem. Health Economics 1996;5:297-305.

10 Chaudhary MA, Stearns SC. Estimating confidence intervals for cost-effectiveness ratios: an example from a randomized trial. Stat Med 1996; 15:1447-58.

11 Van Hout BA, Al MJ, Gordon GS, Rutten FF. Costs, effects and c/e-ratios alongside a clinical trial. Health Economics 1994;3:309-19.

12 UK Prospective Diabetes Study Group. Quality of life in type 2 diabetic patients is affected by complications but not by intensive policies to improve blood glucose or blood pressure control (UKPDS 37). Diabetes Care 1999:22:1125-36.

(Accepted 7 February 2000)

\title{
Effect of beer drinking on risk of myocardial infarction: population based case-control study
}

\author{
Martin Bobak, Zdenka Skodova, Michael Marmot
}

International Centre for Health and Society,

Department of

Epidemiology and

Public Health,

University College

London, London

WC1E 6BT

Martin Bobak

senior lecturer

Michael Marmot

professor

continued over

BMJ 2000;320:1378-9
Many studies have shown an inverse association between alcohol consumption and coronary heart disease, with a possible flattening at higher consumption levels. ${ }^{1}$ It remains unclear, however, whether the protective effect is confined to specific beverages (such as red wine) or relates to ethanol. This question is complicated because wine drinkers may differ from people drinking other beverages or have a different drinking pattern. We addressed this issue by conducting a study in the Czech Republic, a predominantly beer drinking country, and by restricting the analyses to people who did not drink wine or spirits.

\section{Participants, methods, and results}

We conducted a population based case-control study in five Czech districts. All men aged 25-64 who had a first non-fatal myocardial infarction that fulfilled the World Health Organization MONICA (monitoring trends and determinants in cardiovascular disease) criteria of definite or probable infarction ${ }^{2}$ over 18 months were considered eligible. All cases agreed to participate in the study. An age stratified random sample of the population (response rate 77\%) served as controls. Data on cases and controls were collected by identical protocols (details are available elsewhere ${ }^{3}$ ).

Participants reported the frequency of drinking any alcohol (never; less than once a month; once or twice a month; several times a week; almost daily or daily; and twice a day or more often). They also reported how much wine, spirits, and beer they consumed during a typical week. The average consumption of pure alcohol was $148 \mathrm{~g}$ a week, $87 \%$ of which was consumed as beer. The analyses were restricted to non-drinkers and "exclusive" beer drinkers (men who typically do not drink wine or spirits). Participants were categorised into four groups according to their average weekly intake of beer: $<0.5$ 
1 (about $18 \mathrm{~g}$ of alcohol), including non-drinkers; 0.5-3.9 l (18-144 g of alcohol); 4-8.9 l (145-324 $\mathrm{g}$ of alcohol); and $\geqslant 91$ (325 g of alcohol).

The lowest risk was found among men who drank almost daily or daily (adjusted odds ratio 0.38 , 95\% confidence interval 0.19 to 0.75 ) and among men who drank 4-8.9 l of beer a week $(0.34,0.19$ to 0.61 ) (table 1). When beer intake was analysed in narrower categories, the lowest risk was found for weekly consumption of 5-6 1, but because of the small numbers of subjects in each category the confidence intervals were wide (not shown). The results did not change when men with a history of heart disease, stroke, diabetes, or cancer were excluded.

\section{Comment}

In this study of beer drinkers, the lowest risk of myocardial infarction was found among men who drank almost daily or daily and who drank 4-9 1 of beer a week. There was a suggestion that the protective effect was lost in men who drank twice a day or more. This is similar to results of studies of other beverages.

It is unlikely that our results are due to bias or confounding. This was a population based study with highly complete recruitment of incident cases through a myocardial infarction register in a well defined population and with good response rate in controls randomly selected from the population register." Questions on average consumption usually lead to underestimation of the real intake, but the ranking of subjects in terms of long term average intake is reasonably reliable. ${ }^{4}$ Restricting the analysis to exclusive beer drinkers eliminated potential confounding by other beverages. It is unlikely that cases and controls answered questions differently; a cohort study in Bavaria, another beer drinking region, produced similar findings. ${ }^{5}$ These results support the view that the protective effect of alcohol intake is due to ethanol rather than to specific substances present in different types of beverages. ${ }^{1}$

We thank local cardiologists in the participating districts.
Table 1 Numbers of cases and controls (non-drinkers or only beer drinkers), and odds ratios (95\% confidence intervals) of non-fatal myocardial infarction for drinking frequency and average weekly beer consumption

\begin{tabular}{|c|c|c|c|}
\hline & $\begin{array}{c}\text { No of } \\
\text { cases/controls }\end{array}$ & $\begin{array}{l}\text { Odds ratio adjusted for } \\
\text { age and district }\end{array}$ & Fully adjusted odds ratio* \\
\hline \multicolumn{4}{|l|}{ Frequency of drinking } \\
\hline Never & $30 / 63$ & 1.0 & 1.0 \\
\hline Less than once a month & $23 / 48$ & $0.90(0.43$ to 1.87$)$ & $1.14(0.52$ to 2.51$)$ \\
\hline Less than once a week & $26 / 81$ & $0.65(0.32$ to 1.29$)$ & 0.62 (0.29 to 1.33$)$ \\
\hline Several times a week & $68 / 276$ & $0.56(0.32$ to 0.98$)$ & 0.60 (0.32 to 1.12$)$ \\
\hline Almost daily or daily & $37 / 234$ & 0.37 (0.20 to 0.68$)$ & 0.38 (0.19 to 0.74$)$ \\
\hline Twice a day or more & $15 / 31$ & $1.04(0.45$ to 2.37$)$ & $0.99(0.41$ to 2.38$)$ \\
\hline \multicolumn{4}{|c|}{ Average weekly beer consumption } \\
\hline$<0.5$ I/ week & $77 / 181$ & 1.0 & 1.0 \\
\hline 0.5 to $3.9 \mathrm{l} /$ week & $88 / 325$ & 0.68 (0.46 to 1.00$)$ & $0.65(0.42$ to 1.00$)$ \\
\hline 4 to $8.9 \mathrm{l} /$ week & $24 / 178$ & 0.38 (0.22 to 0.65$)$ & 0.34 (0.19 to 0.61$)$ \\
\hline$\geqslant 91 /$ week & $13 / 51$ & $0.65(0.32$ to 1.33$)$ & $0.54(0.25$ to 1.14$)$ \\
\hline
\end{tabular}

*Adjusted for age, district, education, smoking, waist to hip ratio, and personal history of diabetes and high cholesterol concentration.

Contributors: MB, ZS, and MM jointly designed the case-control extension of the Czech MONICA project. MB analysed the data and drafted the paper. ZS coordinated the data collection and participated in the interpretation of the data and writing of the paper. MM initiated the project and participated in data interpretation and writing of the paper. MB will act as guarantor.

Funding: The study was funded by a grant from the Wellcome Trust and by the Czech Ministry of Health. MB was supported by the Wellcome Trust fellowship in clinical epidemiology. MM is supported by an MRC research professorship. Competing interests: None declared.

1 Rimm EB, Klatsky A, Grobbee D, Stampfer MJ. Review of moderate alcohol consumption and reduced risk of coronary heart disease: is the effect due to beer, wine, or spirits? BMJ 1996;312:731-6.

2 World Health Organization. Multinational monitoring of trends and determinants of cardiovascular diseases-"MONICA project." Manual of operations. Version 1.1. CDV/MNC. December 1986. Geneva: WHO, 1987.

3 Bobak M, Skodova Z, Hertzman C, Marmot M. Own education, curren conditions, parental material circumstances and risk of myocardial infarction in a former communist country. J Epidemiol Community Healt 2000;54:91-6.

4 Rehm J, Greenfield TK, Walsh G, Xie X, Robson L, Single E. Assessment methods for alcohol consumption, prevalence of high risk drinking and harm: a sensitivity analysis. Int J Epidemiol 1999;28:219-24.

5 Keil U, Chambless LE, Doering A, Filipiak B, Stieber J. The relation of alcohol intake to coronary heart disease and all-cause mortality in a beer-drinking population. Epidemiology 1997;8:150-6.

(Accepted 16 March 2000)

\section{Department of Preventive Cardiology, Institute of Clinical and Experimental Medicine, 14000 Prague, Czech Republic Zdenka Skodova senior researcher \\ Correspondence to: M Bobak martinb@public- health.ucl.ac.uk}

Generations of children will have read abridged versions of Jonathan Swift's Gulliver's Travels (1767). Sadly, if familiarity prevents rereading then much of the richness in this masterpiece will be missed. For example, few will be aware that Gulliver was a surgeon. Educated at Cambridge, Gulliver studied surgery for four years in London, and then studied medicine for two further years. The story of his adventures is peppered with surgical references. In Brobdingnag (a land populated by giants), Gulliver encounters a woman with a fungating carcinoma of the breast, a man with a wen (sebaceous cyst) on his neck "the size of five woolpacks," and a bilateral amputee with "a couple of wooden legs each about 20 feet high." Gulliver was no stranger to the pressures that characterise modern surgical practice: he worked long hours - "till I was half dead with weariness and vexation"-and he was sued and almost ruined but won his case. In the Academy of Lagado, Gulliver experienced surgical research first hand, narrowly avoiding colonic insufflation for "a small fit of colic." A canine subject was not so fortunate and suffered the fatal consequences. It is, however, matters urological that concern Swift the most. Gulliver's prodigious flow rate saved the life of the Lilliputian queen when fire threatened to engulf the royal household. Unfortunately, his undoing proved to be his undoing; peeing in the palace was tantamount to treason and a rapid escape was required. Swift also recounts the Lilliputians' fascination with our hero's genitalia: the combination of Gulliver's threadbare trousers and the Lilliputians' diminutive stature afforded ample opportunity for surreptitious examination. Finally, the easily distracted Laputians could converse only if a servant constantly held their attention by "flapping" their mouths and ears with an inflated bladder, containing a few calculi, and fastened to a stick. Sixteen years of travel changed Gulliver forever. On his return to England he could not tolerate the company of fellow humans. While not told explicitly, the reader can only conclude that he did not practise surgery again. If Swift were writing today few in the public eye would be spared his brilliant satire. You wonder if his hero would still be a surgeon. Probably. But a urologist? Why not?

Kevin J Turner research fellow in urology, Oxford 